\title{
Development and validation of an analysis method for pesticide residues by gas chromatography-tandem mass spectrometry in Daikenchuto
}

\author{
Hirokazu Saegusa $^{1,2} \cdot$ Hiroshi Nomura $^{2} \cdot$ Masaki Takao $^{2} \cdot$ Takashi Hamaguchi $^{2} \cdot$ Masaru Yoshida $^{3} \cdot$ Yuzo Kodama $^{1}$
}

Received: 5 September 2020 / Accepted: 24 November 2020 / Published online: 3 January 2021

(c) The Author(s) 2021

\begin{abstract}
Daikenchuto (DKT) is one of the most widely used "Kampo" in Japan as a representative of herbal medicine. Because DKT is made from a natural product like food, it requires the management of pesticides; therefore, an analysis of residual pesticides in Kampo is required. The World Health Organization (WHO) indicates that pesticide residue analysis by the U.S. Pharmacopeia (USP) is required. USP defines 107 compounds containing organochlorine pesticides and organophosphorus pesticides and their metabolites, which have a high residual risk. Accordingly, to guarantee the safety of herbal medicines according to global standards is a very important issue. In this study, we developed an analytical method for 91 compounds, which are listed in USP, using DKT as the subject. The method could extract pesticides from DKT with acetone, elute pesticides with acetonitrile using a SepPak C18 column (5 g) and with ethyl acetate using a DSC- $\mathrm{NH}_{2}$ column (2 g), and perform simultaneous analyses by gas chromatography-tandem mass spectrometry (GC-MS/MS). This method, which could quantify 88 compounds, was validated according to USP. A pesticide residue analysis method that meets USP requirements enables the analysis of pesticide residues with a high residue risk and contributes to improving the safety of "Kampo" and other herbal medicines.
\end{abstract}

Keywords Herbal medicine $\cdot$ U.S. pharmacopeia $\cdot$ Matrix effect · Organophosphorous pesticides

\begin{tabular}{ll}
\multicolumn{2}{l}{ Abbreviations } \\
DKT & Daikenchuto \\
EI & Electron ionization \\
GC-MS/MS & $\begin{array}{l}\text { Gas chromatography-tandem mass } \\
\text { spectrometry }\end{array}$ \\
HPLC & $\begin{array}{l}\text { High-performance liquid chromatography } \\
\text { MRL }\end{array}$ \\
\end{tabular}

Hirokazu Saegusa

saegusa_hirokazu@mail.tsumura.co.jp

1 Division of Gastroenterology, Department of Internal Medicine, Kobe University Graduate School of Medicine, 7-5-1 Kusunoki-Cho, Chuo-ku, Kobe, Hyogo 650-0017, Japan

2 CMC Research and Development Laboratories, Tsumura and Co., 3586 Yoshiwara, Ami-machi, Inashiki-gun, Ibaraki 300-1192, Japan

3 Division of Metabolomics Research, Department of Internal Medicine Related, Kobe University Graduate School Medicine, 7-5-1 Kusunoki-Cho, Chuo-ku, Kobe, Hyogo 650-0017, Japan $\begin{array}{ll}\text { PCB } & \text { Polychlorinated biphenyl } \\ \text { RSD } & \text { Relative standard deviation }\end{array}$

\section{Introduction}

Since ancient times, medicinal plants have been employed globally for treatments, and some have been systematized and classified as traditional medicines [1]. Japanese traditional herbal medicine (Kampo) originated from ancient Chinese medicine before it was introduced in Japan around the fifth century. Thereafter, Kampo has become one of the herbal medicines that have accomplished independent development in the country $[2,3]$. Daikenchuto (DKT) is a Kampo that is prepared from three herbal materials, i.e., ginseng, ginger, and Japanese pepper. It is largely utilized in Japan. Daikenchuto has been employed in the improvement of various symptoms of the lower abdominal region, such as bloating, abdominal pain, and constipation [3-5]. In recent years, many clinical study results of DKT regarding digestive tract symptoms in humans have been reported, and an elucidation of its mechanism in gastrointestinal hyperactivity is in progress [3-5]. It is 
expected that DKT will be widely explored in the medical field in the future. Conversely, there is strong demand to secure the safety of medicinal plants themselves and the drugs that are prepared from them because of their usefulness and extensive application [1].

Pesticides, such as microbicides and insecticides, are widely employed in the cultivations of medicinal plants and other farm products. They are essential in ensuring the stable quantity and quality of plants. However, contamination due to pesticide residues is generally a problem. Generally, pesticide residue standards in the food sector of each country are set, based on the acceptable daily intake $[1,6]$. Moreover, regarding medicinal plants, the recommendations of WHO follow the Japanese Pharmacopeia (JP), US Pharmacopeia (USP), and European Pharmacopoeia (EP) [7-9]. US Pharmacopeia and EP target 70 items, including persistently stable organophosphorus and organochlorine pesticides [8, 9].

The 70 items set by USP include major compounds (metabolites and isomers), and a total of 107 compounds are the subject of analysis. Since the 107 compounds are mostly low to medium polar compounds, gas chromatography-tandem mass spectrometry (GC-MS/MS) analysis is required. In the GC-MS/MS analysis, highly polar substances are known to affect the process. Therefore, it is necessary to remove highly polar substances, employing a SPE (solid-phase extraction) column. In the past, the analyses of USP-listed pesticides by GC-MS/MS have been reported in terms of botanical drug substances. One such report was on "Ginseng" where 62 out of the 107 compounds were eluted by a mixed solution of acetone and toluene in a PSA column [10]. The other is a report on "Chenpi" where 67 out of the 107 compounds were purified by a dispersed solid phase [11]. In these reports, since only a few compounds could be analyzed, it became a challenge to expand the number of pesticides that could be analyzed by GC-MS/MS. The purpose of this study is to develop a pretreatment method for 91 USP-listed compounds that can be analyzed by GC-MS/MS, in DKT. Thus far, there has been no report on the development of an analysis method for USPlisted compounds, in DKT. Since DKT contains a wide variety of ingredients, which are derived from Ginseng, ginger, and Japanese pepper, an analysis method for individual raw materials cannot be employed. In this method, to develop a new pretreatment method for DKT, a purification method utilizing ethyl acetate, which is less polar than acetone, as an elution solvent was used. Additionally, the developed analytical method was validated according to USP.

\section{Experimental}

\section{Chemicals and other materials}

Standard reagents of pesticides were purchased, as shown in Table 1. Acetone (pesticide residue and polychlorinated biphenyl (PCB) analysis grade), acetonitrile (pesticide residue and $\mathrm{PCB}$ analysis grade), ethyl acetate (pesticide residue and PCB analysis grade), sodium chloride (guaranteed reagent), and formic acid (high-performance liquid chromatography (HPLC) grade) were purchased from Kanto Chemical Corporation (Tokyo, Japan). Anhydrous sodium sulfate (pesticide residue and PCB analysis grade), methanol (HPLC grade), and $1 \mathrm{~mol} / \mathrm{L}$ ammonium formate solution (HPLC grade) were purchased from FUJIFILM Wako Pure Chemical Corporation (Osaka, Japan). SepPak C18 (5 g) was purchased from Waters (MA, USA). Discovery DSC-NH $\mathrm{N}_{2}(2 \mathrm{~g})$, Discovery DSC-Si (5 g), and l-gulonic acid $\gamma$-lactone were purchased from Sigma-Aldrich (MO, USA). Mega Bond Elut PSA ( $2 \mathrm{~g}$ ) was purchased from Agilent Technologies (CA, USA).

\section{Preparation of pesticide standard solutions}

Each pesticide standard reagent, shown in Table 1, was dissolved in acetone to prepare a $1 \mathrm{mg} / \mathrm{ml}$ stock solution. The respective stock solutions were mixed to prepare a standard solution for addition (four times the analytical concentration). Thereafter, the standard solution for the addition was diluted with acetone to prepare a standard solution with analytical concentration.

\section{Instruments}

Gas chromatography-tandem mass spectrometry (Agilent Technologies 7890GC/7000B, CA, USA) was employed. A DB-XLB (length $30 \mathrm{~m}$, thickness $0.25 \mu \mathrm{m}$, and inner diameter $0.25 \mathrm{~mm}$ ) capillary column (Agilent Technologies, CA, USA) was employed for the separation. The injection mode was pulsed splitless, its volume was $2.0 \mu \mathrm{L}$, and its temperature was $280^{\circ} \mathrm{C}$ [12]. The temperature program of the oven was set at $80^{\circ} \mathrm{C}$ for $2 \mathrm{~min}$, ramped $20 \% \mathrm{~min}$ to $200{ }^{\circ} \mathrm{C}$, ramped $10{ }^{\circ} \mathrm{C} / \mathrm{min}$ to $300{ }^{\circ} \mathrm{C}$, hold at $300{ }^{\circ} \mathrm{C}$ for $5 \mathrm{~min}$, ramped $25^{\circ} \mathrm{C} / \mathrm{min}$ to $325^{\circ} \mathrm{C}$, and held at $325^{\circ} \mathrm{C}$ for $11 \mathrm{~min}$. Further, electron ionization (EI) and multiple reaction monitoring (MRM) modes were employed for quantitation. The EI voltage was $70 \mathrm{eV}$, and the MRM conditions are given in Table 1. MRM is a combination of the precursor and productions. The compound was quantified by MRM1, employing the peak area value. The ratio 
Table 1 Data of USP standard values, suppliers, and MRM conditions of selected pesticides

\begin{tabular}{|c|c|c|c|c|c|c|c|c|}
\hline \multicolumn{2}{|l|}{ USP } & \multirow[t]{2}{*}{ Compounds } & \multirow[t]{2}{*}{ Supplier } & \multirow{2}{*}{$\begin{array}{l}\text { Analytical } \\
\text { concentra- } \\
\text { tion } \\
(\mu \mathrm{g} / \mathrm{mL})\end{array}$} & \multicolumn{4}{|c|}{ MRM conditions } \\
\hline Pesticides & $\begin{array}{l}\mathrm{MRL} \\
(\mathrm{mg} / \mathrm{kg})\end{array}$ & & & & MRM1 & $\mathrm{CE}^{\mathrm{a}}$ & MRM2 & $\mathrm{CE}^{\mathrm{a}}$ \\
\hline Alachlor & 0.05 & Alachlor & $\mathrm{W}$ & 0.05 & $188.0 \rightarrow 160.0$ & 8 & $188.0 \rightarrow 132.0$ & 18 \\
\hline \multirow[t]{2}{*}{ Aldrin and dieldrin (sum of) } & \multirow[t]{2}{*}{0.05} & Aldrin & $\mathrm{D}$ & 0.05 & $293.0 \rightarrow 220.0$ & 24 & $293.0 \rightarrow 258.0$ & 12 \\
\hline & & Dieldrin & A & 0.05 & $263.0 \rightarrow 193.0$ & 28 & $277.0 \rightarrow 241.0$ & 8 \\
\hline Azinphos-ethyl & 0.1 & Azinphos-ethyl & $\mathrm{D}$ & 0.1 & $160.0 \rightarrow 132.0$ & 2 & $132.0 \rightarrow 77.0$ & 14 \\
\hline Azinphos-methyl & 1 & Azinphos-methyl & $\mathrm{W}$ & 1 & $160.0 \rightarrow 132.0$ & 2 & $132.0 \rightarrow 77.0$ & 14 \\
\hline Bromophos-ethyl & 0.05 & Bromophos-ethyl & $\mathrm{D}$ & 0.05 & $359.0 \rightarrow 331.0$ & 6 & $303.0 \rightarrow 239.0$ & 22 \\
\hline Bromophos-methyl & 0.05 & Bromophos-methyl & $\mathrm{D}$ & 0.05 & $331.0 \rightarrow 316.0$ & 18 & $329.0 \rightarrow 314.0$ & 18 \\
\hline Bromopropylate & 3 & Bromopropylate & $\mathrm{K}$ & 3 & $341.0 \rightarrow 183.0$ & 18 & $341.0 \rightarrow 185.0$ & 18 \\
\hline \multirow{3}{*}{$\begin{array}{l}\text { Chlordane (sum of cis-, trans-, } \\
\text { and oxychlordane) }\end{array}$} & \multirow[t]{3}{*}{0.05} & cis-Chlordane & $\mathrm{D}$ & 0.05 & $373.0 \rightarrow 266.0$ & 22 & $375.0 \rightarrow 266.0$ & 22 \\
\hline & & trans-Chlordane & $\mathrm{D}$ & 0.05 & $373.0 \rightarrow 266.0$ & 22 & $375.0 \rightarrow 266.0$ & 22 \\
\hline & & Oxychlordane & A & 0.05 & $389.0 \rightarrow 353.0$ & 6 & $387.0 \rightarrow 323.0$ & 14 \\
\hline \multirow[t]{2}{*}{ Chlorfenvinphos } & \multirow[t]{2}{*}{0.5} & cis-Chlorfenvinphos & W & 0.5 & $267.0 \rightarrow 159.0$ & 16 & $323.0 \rightarrow 267.0$ & 14 \\
\hline & & trans-Chlorfenvinphos & $\mathrm{H}$ & 0.5 & $267.0 \rightarrow 159.0$ & 16 & $323.0 \rightarrow 267.0$ & 14 \\
\hline Chlorpyriphos-ethyl & 0.2 & Chlorpyriphos-ethyl & $\mathrm{W}$ & 0.2 & $314.0 \rightarrow 258.0$ & 14 & $286.0 \rightarrow 258.0$ & 6 \\
\hline Chlorpyriphos-methyl & 0.1 & Chlorpyriphos-methyl & W & 0.1 & $286.0 \rightarrow 93.0$ & 24 & $288.0 \rightarrow 93.0$ & 24 \\
\hline Chlorthal-dimethyl & 0.01 & Chlorthal-dimethyl & $\mathrm{D}$ & 0.01 & $301.0 \rightarrow 223.0$ & 26 & $301.0 \rightarrow 273.0$ & 16 \\
\hline Cyfluthrin (sum of) & 0.1 & Cyfluthrin & $\mathrm{D}$ & 0.1 & $226.0 \rightarrow 206.0$ & 14 & $226.0 \rightarrow 199.0$ & 6 \\
\hline$\lambda$-Cyhalothrin & 1 & Cyhalothrin & $\mathrm{D}$ & 1 & $208.0 \rightarrow 181.0$ & 6 & $197.0 \rightarrow 141.0$ & 14 \\
\hline $\begin{array}{l}\text { Cypermethrin and isomers } \\
\text { (sum of) }\end{array}$ & 1 & Cypermethrin & W & 1 & $181.0 \rightarrow 152.0$ & 26 & $209.0 \rightarrow 116.0$ & 14 \\
\hline \multirow{6}{*}{$\begin{array}{l}\mathrm{DDT} \text { (sum of } o, p^{\prime}-\mathrm{DDE}, p, p^{\prime}- \\
\mathrm{DDE}, o, p^{\prime}-\mathrm{DDD}, p, p^{\prime}-\mathrm{DDD} \\
\left.o, p^{\prime}-\mathrm{DDT}, p, p^{\prime}-\mathrm{DDT}\right)\end{array}$} & \multirow[t]{6}{*}{1} & $o, p^{\prime}-\mathrm{DDE}$ & A & 1 & $246.0 \rightarrow 176.0$ & 28 & $318.0 \rightarrow 248.0$ & 22 \\
\hline & & $p, p^{\prime}-\mathrm{DDE}$ & $\mathrm{W}$ & 1 & $246.0 \rightarrow 176.0$ & 28 & $318.0 \rightarrow 248.0$ & 22 \\
\hline & & $o, p^{\prime}-\mathrm{DDD}$ & $\mathrm{D}$ & 1 & $235.0 \rightarrow 165.0$ & 24 & $237.0 \rightarrow 165.0$ & 24 \\
\hline & & $p, p^{\prime}-\mathrm{DDD}$ & $\mathrm{W}$ & 1 & $235.0 \rightarrow 165.0$ & 24 & $237.0 \rightarrow 165.0$ & 24 \\
\hline & & $o, p^{\prime}$-DDT & $\mathrm{D}$ & 1 & $235.0 \rightarrow 165.0$ & 24 & $237.0 \rightarrow 165.0$ & 24 \\
\hline & & $p, p^{\prime}$-DDT & W & 1 & $235.0 \rightarrow 165.0$ & 24 & $237.0 \rightarrow 165.0$ & 24 \\
\hline Deltamethrin & 0.5 & Deltamethrin & W & 0.5 & $253.0 \rightarrow 93.0$ & 18 & $253.0 \rightarrow 174.0$ & 6 \\
\hline Diazinon & 0.5 & Diazinon & W & 0.5 & $304.0 \rightarrow 179.0$ & 8 & $179.0 \rightarrow 137.0$ & 20 \\
\hline Dicofol & 0.5 & $\begin{array}{l}\text { Dicofol } \\
\text { (4,4'-dichlorobenzophenone) }\end{array}$ & $\mathrm{D}$ & 0.5 & $250.0 \rightarrow 215.0$ & 4 & $252.0 \rightarrow 141.0$ & 12 \\
\hline \multirow{3}{*}{$\begin{array}{l}\text { Endosulfan (sum of isomers and } \\
\text { endsulfan-sulfate) }\end{array}$} & \multirow{3}{*}{3} & $\alpha$-Endosulfan & $\mathrm{W}$ & 3 & $265.0 \rightarrow 194.0$ & 8 & $339.0 \rightarrow 267.0$ & 4 \\
\hline & & $\beta$-Endosulfan & $\mathrm{D}$ & 3 & $265.0 \rightarrow 194.0$ & 10 & $339.0 \rightarrow 267.0$ & 4 \\
\hline & & Endosulfan-sulfate & $\mathrm{D}$ & 3 & $272.0 \rightarrow 237.0$ & 14 & $387.0 \rightarrow 253.0$ & 10 \\
\hline Endrin & 0.05 & Endrin & $\mathrm{D}$ & 0.05 & $281.0 \rightarrow 245.0$ & 10 & $281.0 \rightarrow 209.0$ & 22 \\
\hline Ethion & 2 & Ethion & $\mathrm{W}$ & 2 & $231.0 \rightarrow 175.0$ & 12 & $231.0 \rightarrow 203.0$ & 6 \\
\hline Etrimphos & 0.05 & Etrimphos & $\mathrm{D}$ & 0.05 & $292.0 \rightarrow 181.0$ & 6 & $292.0 \rightarrow 153.0$ & 22 \\
\hline \multirow{2}{*}{$\begin{array}{l}\text { Fenchlorphos (sum of fenchlor- } \\
\text { phos and fenchlorphos oxon) }\end{array}$} & \multirow[t]{2}{*}{0.1} & Fenchlorphos & $\mathrm{D}$ & 0.1 & $287.0 \rightarrow 272.0$ & 16 & $285.0 \rightarrow 240.0$ & 28 \\
\hline & & Fenchlorphos oxon & $\mathrm{D}$ & 0.1 & $269.0 \rightarrow 254.0$ & 18 & $269.0 \rightarrow 224.0$ & 28 \\
\hline Fenitrothion & 0.5 & Fenitrothion & W & 0.5 & $277.0 \rightarrow 260.0$ & 4 & $277.0 \rightarrow 109.0$ & 18 \\
\hline Fenpropathrin & 0.03 & Fenpropathrin & W & 0.03 & $265.0 \rightarrow 210.0$ & 10 & $265.0 \rightarrow 89.0$ & 28 \\
\hline \multirow{4}{*}{$\begin{array}{l}\text { Fensulfothion (sum of fensul- } \\
\text { fothion, fensulfothion oxon, } \\
\text { fensulfothion-oxon-sulfone } \\
\text { and fensulfothion-sulfone) }\end{array}$} & \multirow[t]{4}{*}{0.05} & Fensulfothion & $\mathrm{W}$ & 0.05 & $308.0 \rightarrow 293.0$ & 4 & $293.0 \rightarrow 125.0$ & 12 \\
\hline & & Fensulfothion oxon & $\mathrm{D}$ & 0.05 & $277.0 \rightarrow 249.0$ & 6 & $277.0 \rightarrow 221.0$ & 12 \\
\hline & & Fensulfothion-oxon-sulfone & $\mathrm{D}$ & 0.05 & $308.0 \rightarrow 182.0$ & 4 & $293.0 \rightarrow 229.0$ & 4 \\
\hline & & Fensulfothion-sulfone & $\mathrm{D}$ & 0.05 & $324.0 \rightarrow 170.0$ & 4 & $296.0 \rightarrow 188.0$ & 8 \\
\hline
\end{tabular}


Table 1 (continued)

\begin{tabular}{|c|c|c|c|c|c|c|c|c|}
\hline \multicolumn{2}{|l|}{ USP } & \multirow[t]{2}{*}{ Compounds } & \multirow[t]{2}{*}{ Supplier } & \multirow{2}{*}{$\begin{array}{l}\text { Analytical } \\
\text { concentra- } \\
\text { tion } \\
(\mu \mathrm{g} / \mathrm{mL})\end{array}$} & \multicolumn{4}{|l|}{ MRM conditions } \\
\hline Pesticides & $\begin{array}{l}\mathrm{MRL} \\
(\mathrm{mg} / \mathrm{kg})\end{array}$ & & & & MRM1 & $\mathrm{CE}^{\mathrm{a}}$ & MRM2 & $\mathrm{CE}^{\mathrm{a}}$ \\
\hline \multirow{6}{*}{$\begin{array}{l}\text { Fenthion (sum of fenthion, } \\
\text { fenthion-oxon, fenthion-oxon- } \\
\text { sulfone, fenthion-oxon-sul- } \\
\text { foxide, fenthion-sulfone and } \\
\text { fenthion sulfoxide) }\end{array}$} & \multirow[t]{6}{*}{0.05} & Fenthion & D & 0.05 & $278.0 \rightarrow 109.0$ & 20 & $278.0 \rightarrow 125.0$ & 20 \\
\hline & & Fenthion oxon & W & 0.05 & $262.0 \rightarrow 247.0$ & 10 & $262.0 \rightarrow 217.0$ & 16 \\
\hline & & Fenthion-oxon-sulfone & W & 0.05 & $215.0 \rightarrow 109.0$ & 12 & $294.0 \rightarrow 230.0$ & 6 \\
\hline & & Fenthion-oxon-sulfoxide & W & 0.05 & $263.0 \rightarrow 109.0$ & 16 & $278.0 \rightarrow 263.0$ & 6 \\
\hline & & Fenthion-sulfone & $\mathrm{D}$ & 0.05 & $310.0 \rightarrow 246.0$ & 4 & $310.0 \rightarrow 136.0$ & 18 \\
\hline & & Fenthion sulfoxide & $\mathrm{D}$ & 0.05 & $294.0 \rightarrow 279.0$ & 4 & $279.0 \rightarrow 169.0$ & 14 \\
\hline Fenvalerate & 1.5 & Fenvalerate & W & 1.5 & $225.0 \rightarrow 119.0$ & 18 & $225.0 \rightarrow 147.0$ & 8 \\
\hline Flucythrinate & 0.05 & Flucythrinate & $\mathrm{W}$ & 0.05 & $451.0 \rightarrow 199.0$ & 10 & $225.0 \rightarrow 147.0$ & 8 \\
\hline$\tau$-Fluvalinate & 0.05 & Fluvalinate & $\mathrm{W}$ & 0.05 & $250.0 \rightarrow 55.0$ & 16 & $250.0 \rightarrow 200.0$ & 22 \\
\hline Fonophos & 0.05 & Fonophos & $\mathrm{W}$ & 0.05 & $246.0 \rightarrow 109.0$ & 16 & $246.0 \rightarrow 137.0$ & 4 \\
\hline \multirow{3}{*}{$\begin{array}{l}\text { Heptachlor (sum of heptachlor, } \\
\text { cis-heptachlorepoxide and } \\
\text { trans-heptachlorepoxide) }\end{array}$} & \multirow[t]{3}{*}{0.05} & Heptachlor & $\mathrm{D}$ & 0.05 & $272.0 \rightarrow 237.0$ & 16 & $337.0 \rightarrow 266.0$ & 16 \\
\hline & & cis-Heptachlorepoxide & $\mathrm{D}$ & 0.05 & $353.0 \rightarrow 263.0$ & 14 & $355.0 \rightarrow 265.0$ & 16 \\
\hline & & trans-Heptachlorepoxide & $\mathrm{D}$ & 0.05 & $353.0 \rightarrow 253.0$ & 16 & $355.0 \rightarrow 291.0$ & 8 \\
\hline Hexachlorbenzene & 0.1 & Hexachlorobenzene & $\mathrm{D}$ & 0.1 & $284.0 \rightarrow 249.0$ & 22 & $249.0 \rightarrow 214.0$ & 16 \\
\hline \multirow{4}{*}{$\begin{array}{l}\text { Hexachlorcyclohexane (sum of } \\
\text { isomers } \alpha-, \beta-, \delta \text { - and } \varepsilon^{-} \text {) }\end{array}$} & \multirow[t]{4}{*}{0.3} & $\alpha$-Hexachlorcyclohexane & $\mathrm{D}$ & 0.3 & $219.0 \rightarrow 183.0$ & 6 & $181.0 \rightarrow 145.0$ & 14 \\
\hline & & $\beta$-Hexachlorcyclohexane & $\mathrm{D}$ & 0.3 & $219.0 \rightarrow 183.0$ & 8 & $181.0 \rightarrow 145.0$ & 16 \\
\hline & & $\delta$-Hexachlorcyclohexane & $\mathrm{D}$ & 0.3 & $219.0 \rightarrow 183.0$ & 8 & $181.0 \rightarrow 145.0$ & 16 \\
\hline & & $\varepsilon$-Hexachlorcyclohexane & $\mathrm{K}$ & 0.3 & $219.0 \rightarrow 183.0$ & 8 & $181.0 \rightarrow 145.0$ & 14 \\
\hline $\begin{array}{l}\text { Lindane } \\
\text { ( } \gamma \text {-hexachlorocychlohexane })\end{array}$ & 0.6 & $\gamma$-Hexachlorcyclohexane & W & 0.6 & $219.0 \rightarrow 183.0$ & 6 & $181.0 \rightarrow 145.0$ & 14 \\
\hline \multirow{2}{*}{$\begin{array}{l}\text { Malathion and malaoxon (sum } \\
\text { of) }\end{array}$} & \multirow[t]{2}{*}{1} & Malathion & $\mathrm{D}$ & 1 & $173.0 \rightarrow 99.0$ & 14 & $173.0 \rightarrow 127.0$ & 4 \\
\hline & & Malaoxon & $\mathrm{W}$ & 1 & $268.0 \rightarrow 127.0$ & 6 & $268.0 \rightarrow 99.0$ & 12 \\
\hline Mecarbam & 0.05 & Mecarbam & $\mathrm{D}$ & 0.05 & $329.0 \rightarrow 131.0$ & 14 & $296.0 \rightarrow 196.0$ & 6 \\
\hline Methacriphos & 0.05 & Methacriphos & $\mathrm{D}$ & 0.05 & $240.0 \rightarrow 208.0$ & 2 & $208.0 \rightarrow 180.0$ & 4 \\
\hline Methidathion & 0.2 & Methidathion & $\mathrm{D}$ & 0.2 & $145.0 \rightarrow 85.0$ & 6 & $145.0 \rightarrow 58.0$ & 14 \\
\hline Methoxychlor & 0.05 & Methoxychlor & W & 0.05 & $227.0 \rightarrow 169.0$ & 28 & $227.0 \rightarrow 212.0$ & 16 \\
\hline Mirex & 0.01 & Mirex & $\mathrm{D}$ & 0.01 & $272.0 \rightarrow 237.0$ & 16 & $332.0 \rightarrow 297.0$ & 22 \\
\hline \multirow{2}{*}{$\begin{array}{l}\text { Parathion-ethyl and paraoxon- } \\
\text { ethyl (sum of) }\end{array}$} & \multirow[t]{2}{*}{0.5} & Parathion-ethyl & W & 0.5 & $291.0 \rightarrow 109.0$ & 12 & $291.0 \rightarrow 81.0$ & 28 \\
\hline & & Paraoxon-ethyl & $\mathrm{D}$ & 0.5 & $275.0 \rightarrow 99.0$ & 16 & $275.0 \rightarrow 149.0$ & 4 \\
\hline \multirow{2}{*}{$\begin{array}{l}\text { Parathion-methyl and paraoxon- } \\
\text { methyl (sum of) }\end{array}$} & \multirow[t]{2}{*}{0.2} & Parathion-methyl & W & 0.2 & $263.0 \rightarrow 109.0$ & 10 & $246.0 \rightarrow 216.0$ & 4 \\
\hline & & Paraoxon-methyl & $\mathrm{F}$ & 0.2 & $230.0 \rightarrow 200.0$ & 6 & $230.0 \rightarrow 136.0$ & 10 \\
\hline Pentachloranisole & 0.01 & Pentachloroanisole & $\mathrm{D}$ & 0.01 & $265.0 \rightarrow 237.0$ & 14 & $280.0 \rightarrow 237.0$ & 26 \\
\hline \multirow{2}{*}{$\begin{array}{l}\text { Permethrin and isomers (sum } \\
\text { of) }\end{array}$} & \multirow[t]{2}{*}{1} & cis-Permethrin & $\mathrm{D}$ & 1 & $183.0 \rightarrow 168.0$ & 14 & $163.0 \rightarrow 127.0$ & 6 \\
\hline & & trans-Permethrin & W & 1 & $183.0 \rightarrow 168.0$ & 14 & $163.0 \rightarrow 127.0$ & 6 \\
\hline Phosalone & 0.1 & Phosalone & W & 0.1 & $182.0 \rightarrow 111.0$ & 16 & $367.0 \rightarrow 182.0$ & 6 \\
\hline Phosmet & 0.05 & Phosmet & W & 0.05 & $160.0 \rightarrow 133.0$ & 14 & $317.0 \rightarrow 160.0$ & 4 \\
\hline Pirimiphos-ethyl & 0.05 & Pirimiphos-ethyl & $\mathrm{D}$ & 0.05 & $318.0 \rightarrow 166.0$ & 14 & $333.0 \rightarrow 180.0$ & 6 \\
\hline \multirow{2}{*}{$\begin{array}{l}\text { Pirimiphos-methyl(sum of piri- } \\
\text { miphos-methyl and } N \text {-dese- } \\
\text { thyl-pirimiphos-methyl) }\end{array}$} & \multirow[t]{2}{*}{4} & Pirimiphos-methyl & $\mathrm{D}$ & 4 & $290.0 \rightarrow 233.0$ & 10 & $305.0 \rightarrow 290.0$ & 8 \\
\hline & & $N$-desethyl-pirimiphos-methy & $\mathrm{D}$ & 4 & $277.0 \rightarrow 168.0$ & 6 & $277.0 \rightarrow 262.0$ & 8 \\
\hline Procymidone & 0.1 & Procymidone & $\mathrm{D}$ & 0.1 & $283.0 \rightarrow 96.0$ & 10 & $283.0 \rightarrow 255.0$ & 10 \\
\hline Profenophos & 0.1 & Profenophos & $\mathrm{W}$ & 0.1 & $339.0 \rightarrow 269.0$ & 14 & $339.0 \rightarrow 311.0$ & 4 \\
\hline Prothiophos & 0.05 & Prothiophos & W & 0.05 & $267.0 \rightarrow 239.0$ & 8 & $309.0 \rightarrow 239.0$ & 16 \\
\hline Quinalphos & 0.05 & Quinalphos & $\mathrm{D}$ & 0.05 & $298.0 \rightarrow 156.0$ & 6 & $270.0 \rightarrow 189.0$ & 8 \\
\hline
\end{tabular}


Table 1 (continued)

\begin{tabular}{|c|c|c|c|c|c|c|c|c|}
\hline \multicolumn{2}{|l|}{ USP } & \multirow[t]{2}{*}{ Compounds } & \multirow[t]{2}{*}{ Supplier } & \multirow{2}{*}{$\begin{array}{l}\text { Analytical } \\
\text { concentra- } \\
\text { tion } \\
(\mu \mathrm{g} / \mathrm{mL})\end{array}$} & \multicolumn{4}{|c|}{ MRM conditions } \\
\hline Pesticides & $\begin{array}{l}\text { MRL } \\
(\mathrm{mg} / \mathrm{kg})\end{array}$ & & & & MRM1 & $\mathrm{CE}^{\mathrm{a}}$ & MRM2 & $\mathrm{CE}^{\mathrm{a}}$ \\
\hline \multirow{3}{*}{$\begin{array}{l}\text { Quintozene (sum of quintozene, } \\
\text { pentachloroaniline and meth- } \\
\text { ylpentachlorophenyl sulfide) }\end{array}$} & 1 & Quintozene & W & 1 & $295.0 \rightarrow 237.0$ & 18 & $295.0 \rightarrow 265.0$ & 8 \\
\hline & & Pentachloroaniline & W & 1 & $265.0 \rightarrow 194.0$ & 24 & $267.0 \rightarrow 194.0$ & 24 \\
\hline & & $\begin{array}{l}\text { Methyl Pentachlorophenyl } \\
\text { sulfide }\end{array}$ & $\mathrm{F}$ & 1 & $296.0 \rightarrow 263.0$ & 16 & $296.0 \rightarrow 246.0$ & 28 \\
\hline$s-421$ & 0.02 & $s-421$ & $\mathrm{D}$ & 0.02 & $211.0 \rightarrow 79.0$ & 6 & $181.0 \rightarrow 85.0$ & 8 \\
\hline Tecnazene & 0.05 & Tecnazene & W & 0.05 & $261.0 \rightarrow 203.0$ & 14 & $215.0 \rightarrow 179.0$ & 10 \\
\hline Tetradifon & 0.3 & Tetradifon & W & 0.3 & $227.0 \rightarrow 199.0$ & 16 & $356.0 \rightarrow 159.0$ & 12 \\
\hline Vinclozolin & 0.4 & Vinclozolin & D & 0.4 & $285.0 \rightarrow 212.0$ & 12 & $212.0 \rightarrow 172.0$ & 14 \\
\hline
\end{tabular}

${ }^{\mathrm{a} C}$ Collision energy

MRL = maximum residue limit

$A$ AccuStandard Inc. (New Haven, USA), $D$ Dr. Ehrenstorfer (Augsburg, Germany), $F$ Fluka Biochemika (Buchs, Switzerland), $H$ Hayashi pure chemical (Osaka, Japan), $K$ Kanto Chemical (Tokyo, Japan), W FUJIFILM Wako Pure Chemical Corporation (Osaka, Japan)

of the peak area value of MRM2 to that of MRM1 was qualitatively compared to the standard solution.

\section{Sample treatment and preparation}

\section{Evaluation of the C18 SPE column purification process with a standard solution}

A standard solution or acetonitrile $(20 \mathrm{~mL})$ was added to the SepPak C18 (5 g) columns to activate them. Thereafter, $40 \mathrm{~mL}$ of acetonitrile was added, and the eluent was collected in a flask. Afterward, $40 \mathrm{~mL}$ of acetone was added for the elution, and the eluent was collected in another flask. The eluent in the flask was concentrated and dissolved in acetone for the GC-MS/MS measurement.

\section{Liquid-liquid distribution and the dehydration process with the standard solution}

The standard solution, $10 \mathrm{~mL}$ of acetonitrile, $10 \mathrm{~mL}$ of saturated sodium chloride solution, and $25 \mathrm{~mL}$ of ethyl acetate were mixed in a centrifuge tube. The mixture was shaken and the upper layer was collected in a new flask. Anhydrous sodium sulfate was added, and the mixture was filtrated. Further, $25 \mathrm{~mL}$ of ethyl acetate was added and shaken. The upper layer was collected in the flask and was dehydrated by anhydrous sodium sulfate.

\section{Purification column tests}

The standard solutions and $20 \mathrm{~mL}$ of ethyl acetate were added to each purification columns that had been activated with ethyl acetate. Next, $20 \mathrm{~mL}$ of ethyl acetate was added, and the eluent was collected in a new flask. The eluent was concentrated and dissolved in acetone for the GC-MS/MS measurement.

\section{Recovery test}

The recovery test in DKT was performed, as shown in Fig. 1. The detailed steps are given as follows: DKT was crushed with a mortar and pestle, a 2 g portion, which was placed in a centrifuge tube, was accurately weighed. For the recovery test, the standard solutions were added to the centrifuge tube, after which $20 \mathrm{~mL}$ of acetone was added to the tube; shaken for $10 \mathrm{~min}$, at $200 \mathrm{rpm}$; and centrifuged for $5 \mathrm{~min}$, at 3,000 rpm. The supernatant was collected in a new flask, and $20 \mathrm{~mL}$ of acetone was placed in the centrifuge tube, shaken for $10 \mathrm{~min}$, at $200 \mathrm{rpm}$, and centrifuged for $5 \mathrm{~min}$, at 3,000 rpm. The supernatant obtained from the second extraction was mixed with that from the first; concentrated, at reduced pressure; and redissolved in $20 \mathrm{~mL}$ of acetonitrile. The acetonitrile solution was applied to a SepPak C18 (5 g) solid-phase extraction column, which had been activated with acetonitrile, and the eluate was collected in a flask. Further, $40 \mathrm{~mL}$ of acetonitrile was applied to the SepPak C18 (5 g) column, and the eluate was collected in the same flask. This eluate was concentrated, at reduced pressure; transferred into a centrifuge tube; and $10 \mathrm{~mL}$ of saturated sodium chloride solution and $25 \mathrm{~mL}$ of ethyl acetate were added. The mixture was shaken for $10 \mathrm{~min}$, at $200 \mathrm{rpm}$; centrifuged for $5 \mathrm{~min}$, at 3,000 rpm; and the upper layer was transferred into a new flask. Next, $25 \mathrm{~mL}$ of ethyl acetate was added again, and the mixture was shaken for $10 \mathrm{~min}$, at $200 \mathrm{rpm}$; centrifuged for $5 \mathrm{~min}$, at 3,000 rpm; and the upper layer was transferred into the 
Fig. 1 Sample preparation flow

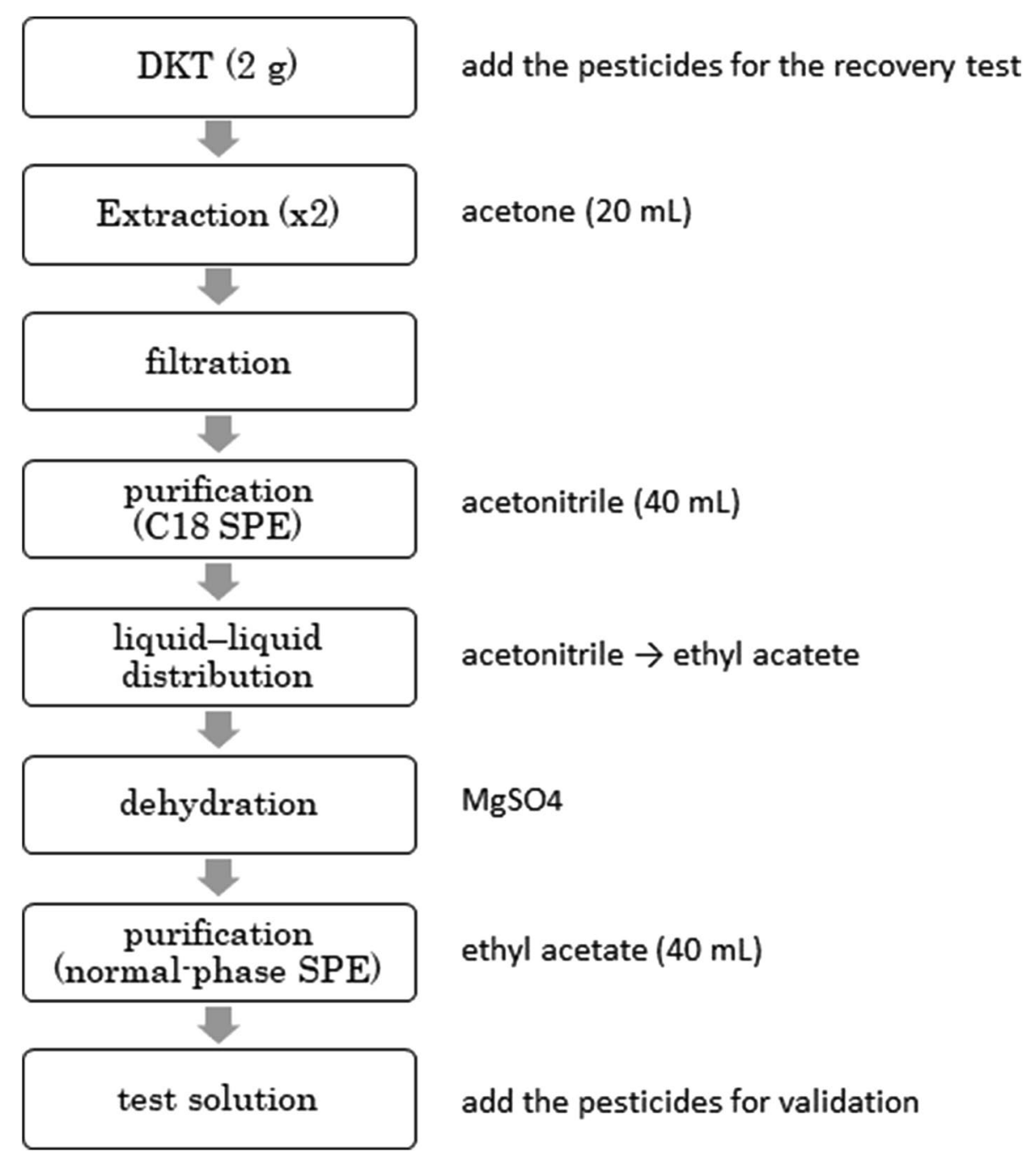

same flask. Anhydrous sodium sulfate was subsequently added to the flask in which the upper layer had been collected, followed by mixing and filtration.

The filtrate was applied to a purification column [DSC$\mathrm{NH}_{2}$ (2 g), Mega Bond Elut PSA (2 g), or DSC-Si (5 g)], which had been activated with ethyl acetate, and the eluate was collected in a flask. Further, $40 \mathrm{~mL}$ of ethyl acetate was added, and the eluate was collected in the same flask. The eluate was concentrated, at reduced pressure; dissolved in $5 \mathrm{~mL}$ of acetone; and concentrated again, at reduced pressure. When the purification column was not employed, the filtrate was concentrated, dissolved in $5 \mathrm{~mL}$ of acetone, and concentrated again, at reduced pressure. Acetone was added to the concentrate to obtain exactly $2 \mathrm{~mL}$.

For linearity evaluation and matrix effect verification, the standard solutions, corresponding to $10 \%, 20 \%, 50 \%, 75 \%$, $100 \%, 125 \%$, and $150 \%$ of the analytical concentration, were added. Additionally, while validating, $0.1 \%$ L-gulonic acid $\gamma$-lactone was added.

\section{Results and discussion}

\section{Development of the pretreatment method}

For the extraction method (referring to USP), $20 \mathrm{~mL}$ of acetone was utilized for $2 \mathrm{~g}$ of DKT [8]. First, the recovery rates of each pretreatment step were obtained, employing only the pesticide standard solution, to investigate the interaction of the pesticides with each preparation step. Afterward, a recovery test, utilizing DKT, was performed to investigate the influence of the matrix derived from DKT. The evaluation criteria to validate the method were 70-120\%, for recovery test employing DKT. In developing an analytical method, a recovery of 70-120\% must be achieved with a combination of multiple treatments. Therefore, the acceptance criterion for the recovery rate in each process without DKT was set at $\geq 80 \%$. 


\section{Evaluation of the C18 SPE column purification process with the standard solution}

The C18 column purification process is generally employed to purify pesticides from extracts [13]. To efficiently purify the extract, a SepPak C18 (5 g) column with a large amount of silica gel support was selected. Acetonitrile, generally employed for pesticide residue analysis in food was utilized for the elution. An additional elution was performed with acetone, which was used in the extraction process. To confirm the elution pattern of the pesticides in the C18 column purification step, the pesticide standard solution was added to the $\mathrm{C} 18$ column, and the recovery rates of each pesticide with acetonitrile and acetone were determined. The recovery rate was the average of the results of the two tests.

The recovery rate is $\geq 80 \%$ for 90 of 91 tested compounds (data not shown). The recovery rates of bromopropylate with acetonitrile and acetone are $47.6 \%$ and $27.0 \%$, respectively. Bromopropylate exhibits a high affinity for the C18 column, and it has been demonstrated that the recovery rate may be unstable in the recovery test with DKT.

\section{Evaluation of the liquid-liquid distribution and the dehydration process with the standard solution}

The liquid-liquid distribution, from aqueous phase to organic phase, and the dehydration steps were demonstrated for the purpose of utilizing the normal-phase column process in the next step. The recovery test, utilizing the pesticide standard solution, for the liquid-liquid distribution and dehydration was conducted [14]. The recovery rate was the average of the results of the three tests.

The recovery rate is $\geq 80 \%$ for 86 of the 91 tested compounds (data not shown). The compounds whose recovery rates in the first distribution operation were $<80 \%$ were fensulfothion $(72.1 \%)$, fensulfothion oxon $(60.2 \%)$, fensulfothion-oxon-sulfone (78.2\%), fenthion-oxon-sulfoxide (66.4\%), and fenthion sulfoxide (78.1\%). Each of the compounds was not recovered in the second and third operations.

The recovery rates of fensulfothion, fensulfothion oxon, fensulfothion-oxon-sulfone, fenthion-oxon-sulfoxide, and fenthion sulfoxide did not increase even after repeated partitioning operations. It was speculated that the efficiency of the liquid-liquid distribution was not responsible for the decrease in the recovery rate.

\section{Evaluation of the normal-phase column purification process with the standard solution}

DSC-NH $\mathrm{N}_{2}(2 \mathrm{~g})$, Mega Bond Elut PSA ( $\left.2 \mathrm{~g}\right)$, and DSC-Si $(5 \mathrm{~g})$ were selected as the normal-phase columns to retain highly polar substances [15], and ethyl acetate was selected as the eluting solvent [15]. To confirm the elution pattern of the pesticide in the normal-phase column purification process, the standard solution was added to the normal-phase column, and the recovery rate of each compound with ethyl acetate was determined. The recovery rate is the average of the results of the three tests.

The recovery rates with $\mathrm{DSC}-\mathrm{NH}_{2}(2 \mathrm{~g})$ are $>80 \%$ for all the compounds (data not shown). The compounds whose rates were $<80 \%$ in the Bond Elut PSA ( $2 \mathrm{~g})$ column are fenchlorphos oxon $(79.5 \%)$ and delta-BHC $(78.2 \%)$ and those whose rates were $<80 \%$ in DSC-Si $(5 \mathrm{~g})$ were $N$-desethyl-pirimiphos-methyl (0.3\%), fenthion-oxon (74.7\%), fensulfothion oxon (0\%), and fenthion-oxon-sulfoxide (14.1\%). In the study with the standard solution, the method of elution, employing $2 \mathrm{~g}$ of DSC- $\mathrm{NH}_{2}$ with ethyl acetate, was the most appropriate.

\section{Evaluation of the pretreatment methods}

The recovery test in DKT was conducted in the case of using no purification column, DSC- $\mathrm{NH}_{2}(2 \mathrm{~g})$, Mega Bond Elut PSA ( $2 \mathrm{~g})$, and DSC-Si ( $5 \mathrm{~g})$. These evaluations included the $\mathrm{C} 18$ column purification and the liquid-liquid distribution processes, as shown in Fig. 1. The recovery rate was the average of the results of the three tests (Table 2).

DSC- $\mathrm{NH}_{2}(2 \mathrm{~g})$ was mostly pesticides with recovery rates of $70-120 \%$ (Table 2). The recovery rates of cyhalothrin, deltamethrin, delta-BHC, and profenophos were $<70 \%$ with DKT (Table 2) but were > $80 \%$ without DKT. It was speculated that the DKT-derived matrices affected the pretreatment and GC-MS/MS analysis processes. The combination of the SepPak C18 (5 g) column and DSC-NH $\mathrm{N}_{2}(2 \mathrm{~g})$ column was the most excellent pretreatment method for the removal of the interfering components derived from DKT to ensure the recovery of the pesticide to be analyzed. DSC- $\mathrm{NH}_{2}$ and Mega Bond Elut PSA are silica-based sorbents modified with an amino propyl group and an ethylenediamine- $N$-propyl group, respectively. Both sorbents exhibit a weak nonpolar interaction in nonpolar solvents. However, their different structure may cause a difference in the ability to remove the matrices in the DKT. In addition, since DSC-Si has a strong polar interaction even in nonpolar solvents, highly polar pesticides are strongly retained, and the recovery rate is low.

\section{Validation}

In the GC analysis, a calculated value may be lower or higher than the true value due to the matrix effect [16]. Stable isotopes, matrix calibration curve, or matrix effect inhibitors is a method of solving the challenge of matrix effect [16-18]. However, it is challenging to prepare the stable isotopes of 107 compounds. Moreover, when preparing the matrix calibration curve, the representative samples that generally exhibit constant matrix effects are required 
Table 2 Evaluation of the purification columns

\begin{tabular}{|c|c|c|c|}
\hline \multirow{2}{*}{$\begin{array}{l}\text { Purification column process } \\
\text { No column }\end{array}$} & \multicolumn{2}{|c|}{$\begin{array}{l}\text { Events outside the evalu- } \\
\text { ation range }\end{array}$} & \multirow{2}{*}{$\begin{array}{l}\text { Compounds outside the evaluation range }^{\mathrm{a}} \\
\text { Fenthion oxon (63.5), heptachlor (56.3), pirimiphos-methyl (66.8), and pro- } \\
\text { fenophos(44.7) }\end{array}$} \\
\hline & Recovery rate & $<70 \%$ & \\
\hline & & $>120 \%$ & $\begin{array}{l}\text { cis-Chlorfenvinphos (136.6), fensulfothion oxon (132.5), and fenthion-oxon-sulfoxide } \\
\text { (122.2) }\end{array}$ \\
\hline & RSD & $>20 \%$ & - \\
\hline \multirow[t]{3}{*}{ Mega Bond Elut PSA (2 g) } & Recovery rate ${ }^{b}$ & $<70 \%$ & $\begin{array}{l}\text { Delta-BHC (65.9), fenchlorphos oxon (38.2), paraoxon-methyl (45.8), phosmet (40.5), } \\
\text { and profenophos (19.2) }\end{array}$ \\
\hline & & $>120 \%$ & Fensulfothion (126.0) and fensulfothion oxon (142.2) \\
\hline & RSD & $>20 \%$ & - \\
\hline \multirow[t]{3}{*}{ DSC-NH ${ }_{2}(2 \mathrm{~g})$} & Recovery rate ${ }^{b}$ & $<70 \%$ & Cyhalothrin (67.8), deltamethrin (65.9), delta-BHC (63.2), and profenophos (26.9) \\
\hline & & $>120 \%$ & Dicofol (122.1) \\
\hline & RSD & $>20 \%$ & - \\
\hline \multirow[t]{3}{*}{ DSC-Si (5 g) } & Recovery rate ${ }^{b}$ & $<70 \%$ & $\begin{array}{l}\text { Fensulfothion (39.3), fensulfothion oxon (0), fenthion oxon(55.1), fenthion-oxon- } \\
\text { sulfoxide (3.0), fenthion sulfoxide (26.5), heptachlor (56.7), } N \text {-desethyl-pirimiphos } \\
\text { methyl (4.6), and pirimiphos-methyl (67.5) }\end{array}$ \\
\hline & & $>120 \%$ & $\begin{array}{l}\text { cis-Chlorfenvinphos (134.4), dicofol (154.9), endrin (121.5), fenthion-oxon-sulfone } \\
\text { (124.8), flucythrinate (122.0), and fluvalinate(124.4) }\end{array}$ \\
\hline & RSD & $>20 \%$ & $\begin{array}{l}\text { Fensulfothion (26.7), fenthion-oxon-sulfoxide (21.5), fenthion sulfoxide (39.4), } N \text {-dese- } \\
\text { thyl-pirimiphos-methyl (81.4) }\end{array}$ \\
\hline
\end{tabular}

${ }^{\mathrm{a}}$ Number of bracket were recovery rate (\%)

${ }^{b}$ For the underlined compounds, the recovery rates without DKT were $<80 \%$

Table 3 Evaluation criteria for validation

\begin{tabular}{ll}
\hline Validation parameters & Validation criteria \\
\hline Linearity & $\leq \pm 20 \% \mathrm{a}$ \\
Recovery & $70-120 \%(n=3)$ \\
Precision & $\leq 20 \%(n=3)$ \\
Ion ratio & $\pm 30 \%{ }^{\mathrm{b}}$ \\
Retention time & $< \pm 0.1 \min ^{\mathrm{c}}$ \\
LOQ & $\leq \mathrm{MRL}^{\mathrm{d}}$ \\
\hline
\end{tabular}

${ }^{a}$ Deviation of back-calculated concentration from the true concentration

${ }^{\mathrm{b}}$ Ion ratio of the samples should be within $\pm 30 \%$ of the standards

${ }^{\mathrm{c}}$ Retention time of the samples should be within $\pm 0.1 \mathrm{~min}$ of the standards

${ }^{\mathrm{d}}$ Lowest concentration $(\mathrm{mg} / \mathrm{kg})$ satisfying the other criteria

$[17,19]$. Therefore, in this study, the matrix effect inhibitor (L-gulonic acid $\gamma$-lactone) was employed for the validation of the test method. [19] Additionally, to deepen the discussion, the matrix effect of each pesticide was evaluated.

The validation was conducted based on the evaluation criteria, as shown in Table $3,[8,17,20]$. For the evaluation of the linearity, standard solutions corresponding to $10 \%, 20 \%, 50 \%, 75 \%, 100 \%, 125 \%$, and $150 \%$ of the maximum residue limits (MRLs) were added to acetone and the sample solution, respectively. From each analysis, a deviation in the back-calculated concentration, from the true concentration, was calculated (Table 4). Further, for the evaluation of the true value and specificity, the standard solutions corresponding to $10 \%, 20 \%$, $50 \%, 100 \%$, and $150 \%$ of the MRLs were added to each sample, respectively. The recovery and relative standard deviation ( $\mathrm{RSD})(n=3$, for each concentration) were also calculated (Table 4). They were calculated only when the ion ratio and retention time satisfied the criteria, as shown in Table 3. For the evaluation of the matrix effect, the standard solutions corresponding to $10 \%, 20 \%, 50 \%, 75 \%$, $100 \%, 125 \%$, and $150 \%$ of MRLs were added to acetone and the sample solution, respectively. The recovery rate of the sample solution to acetone was calculated at each concentration, and the deviation, from $100 \%$, was assumed to be the matrix effect (Table 5).

The recovery rates of fenchlorphos oxon and paraoxonmethyl did not decrease in the recovery test in DKT without L-gulonic acid $\gamma$-lactone (Table 2), and it decreased in that with L-gulonic acid $\gamma$-lactone (Table 4). Moreover, the value of the matrix effect was low, at all concentrations (Table 5). From the above, it is suspected that the combination of the components in DKT and L-gulonic acid $\gamma$-lactone could have affected the GC-MS/MS analysis and decreased the recovery rate.

The recovery rate of profenophos decreased, even when L-gulonic acid $\gamma$-lactone was not utilized. Therefore, we presumed that L-gulonic acid $\gamma$-lactone was not the cause of the decrease in the recovery rate of profenophos, and the 


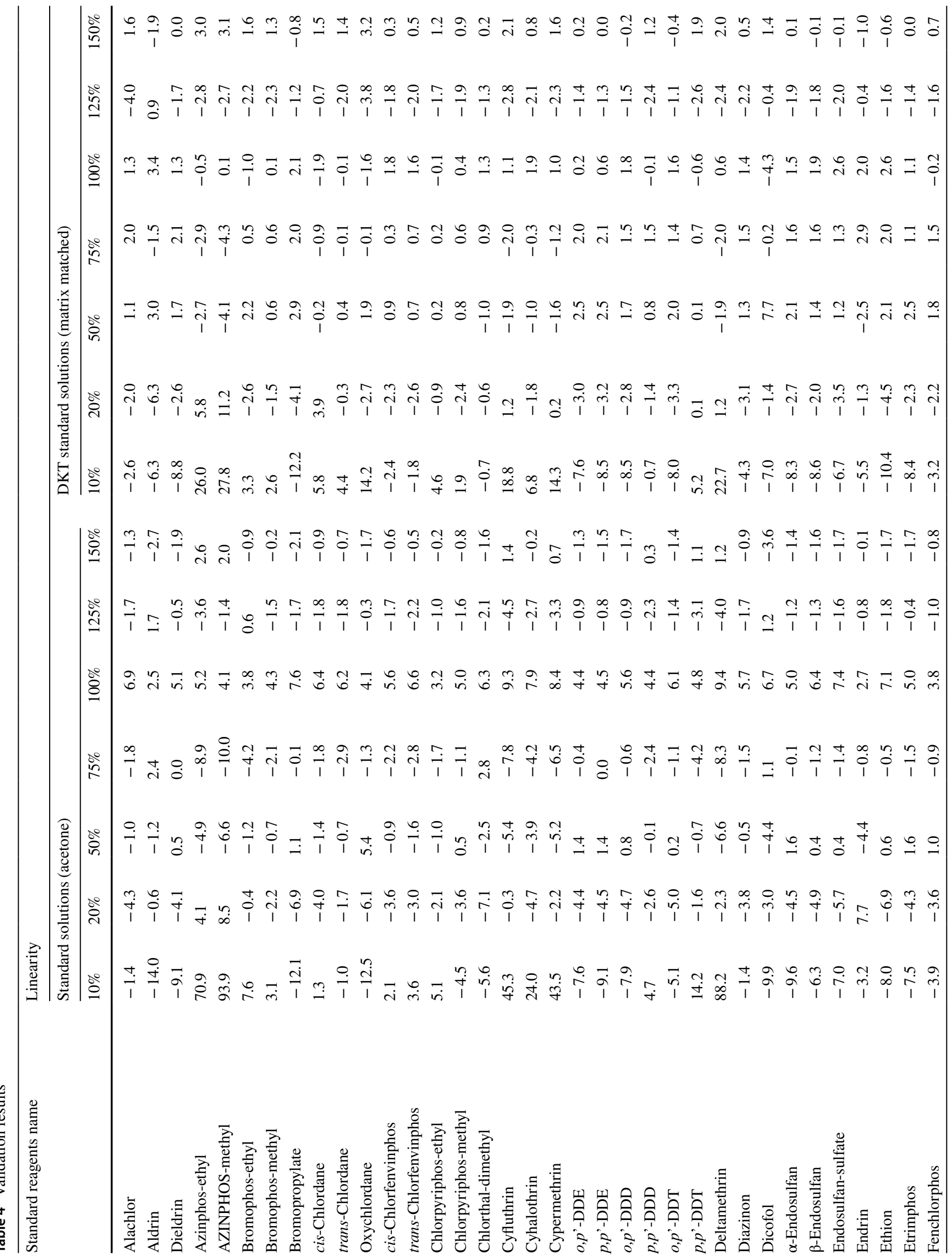




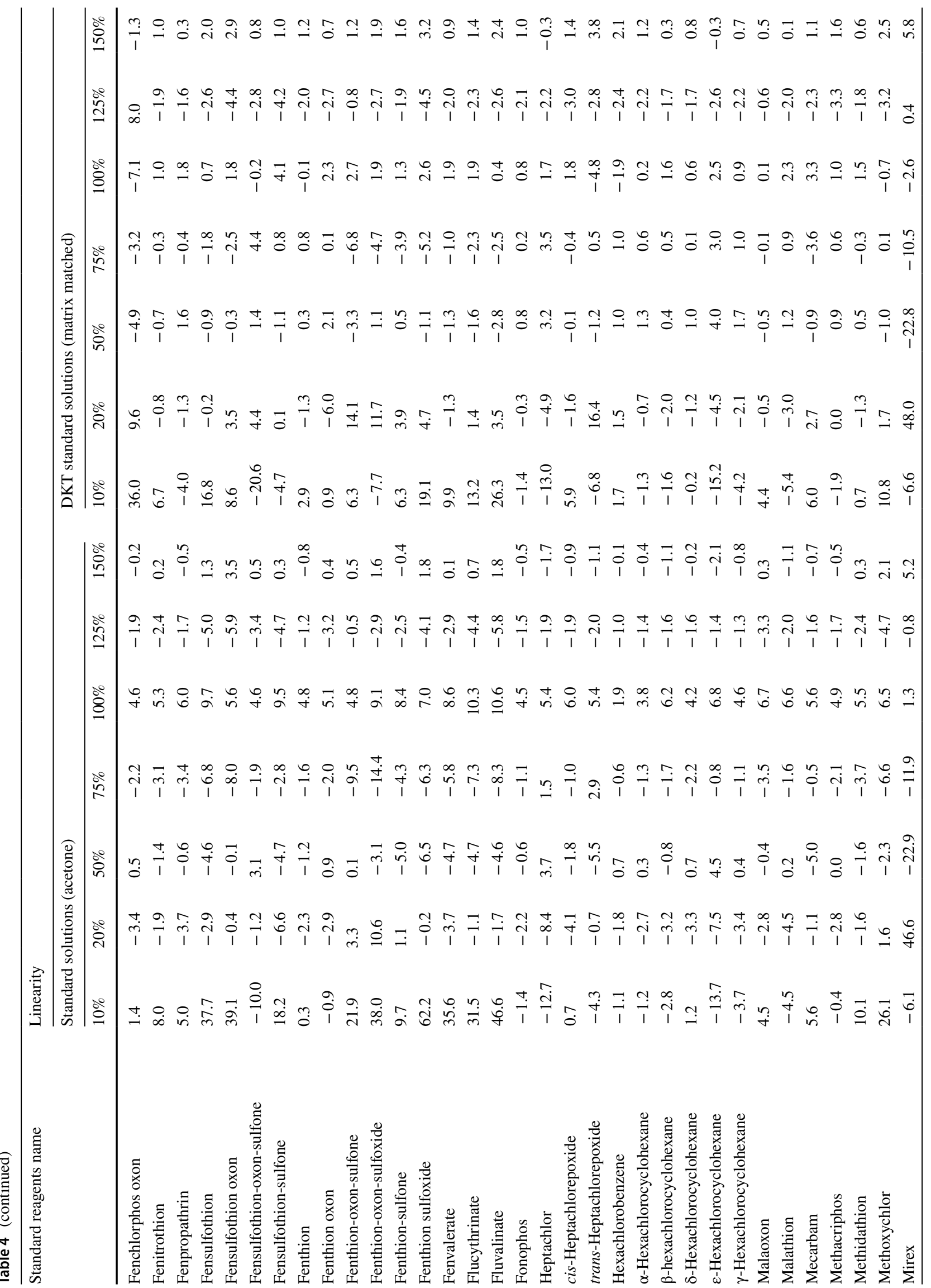




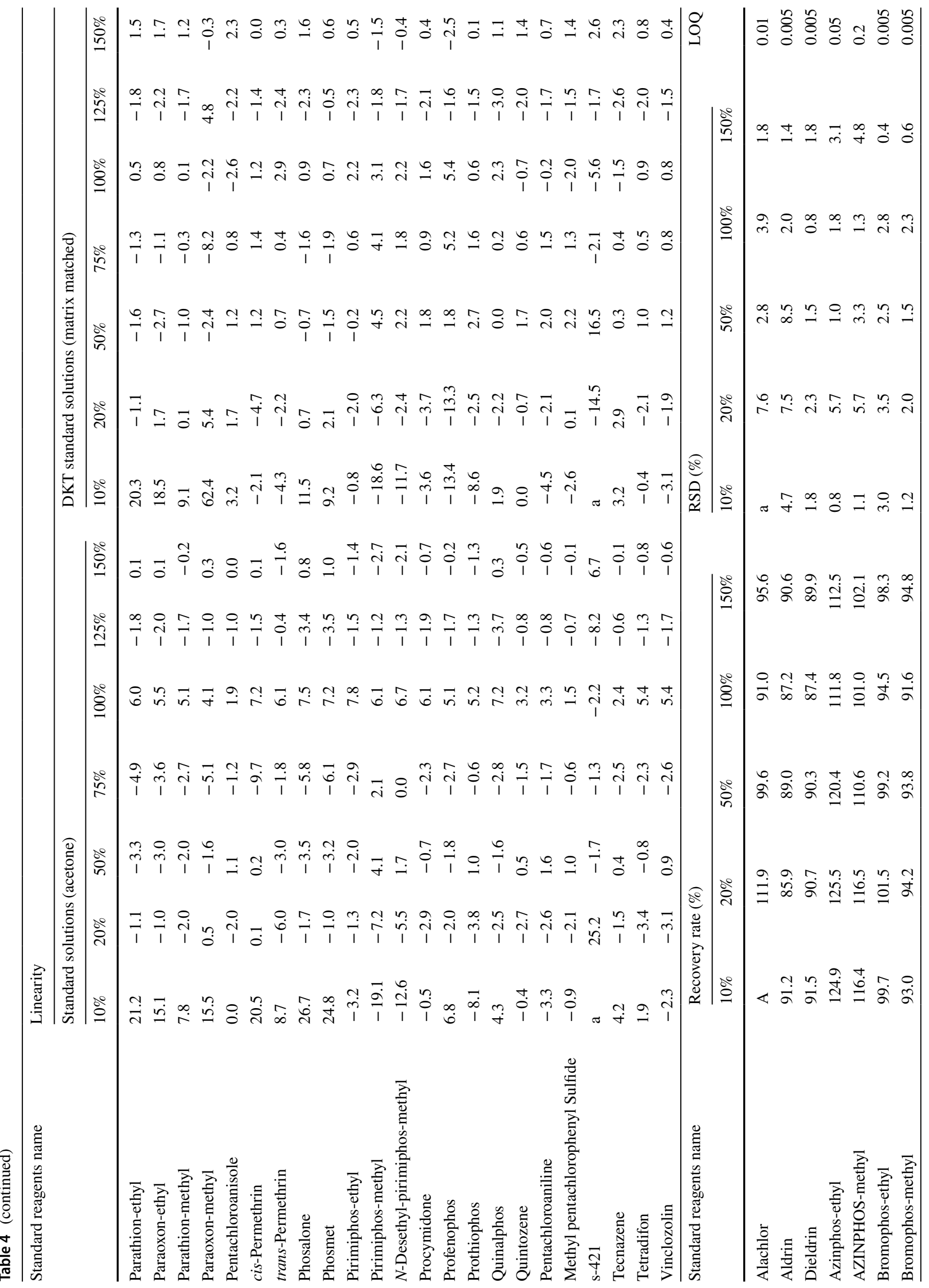




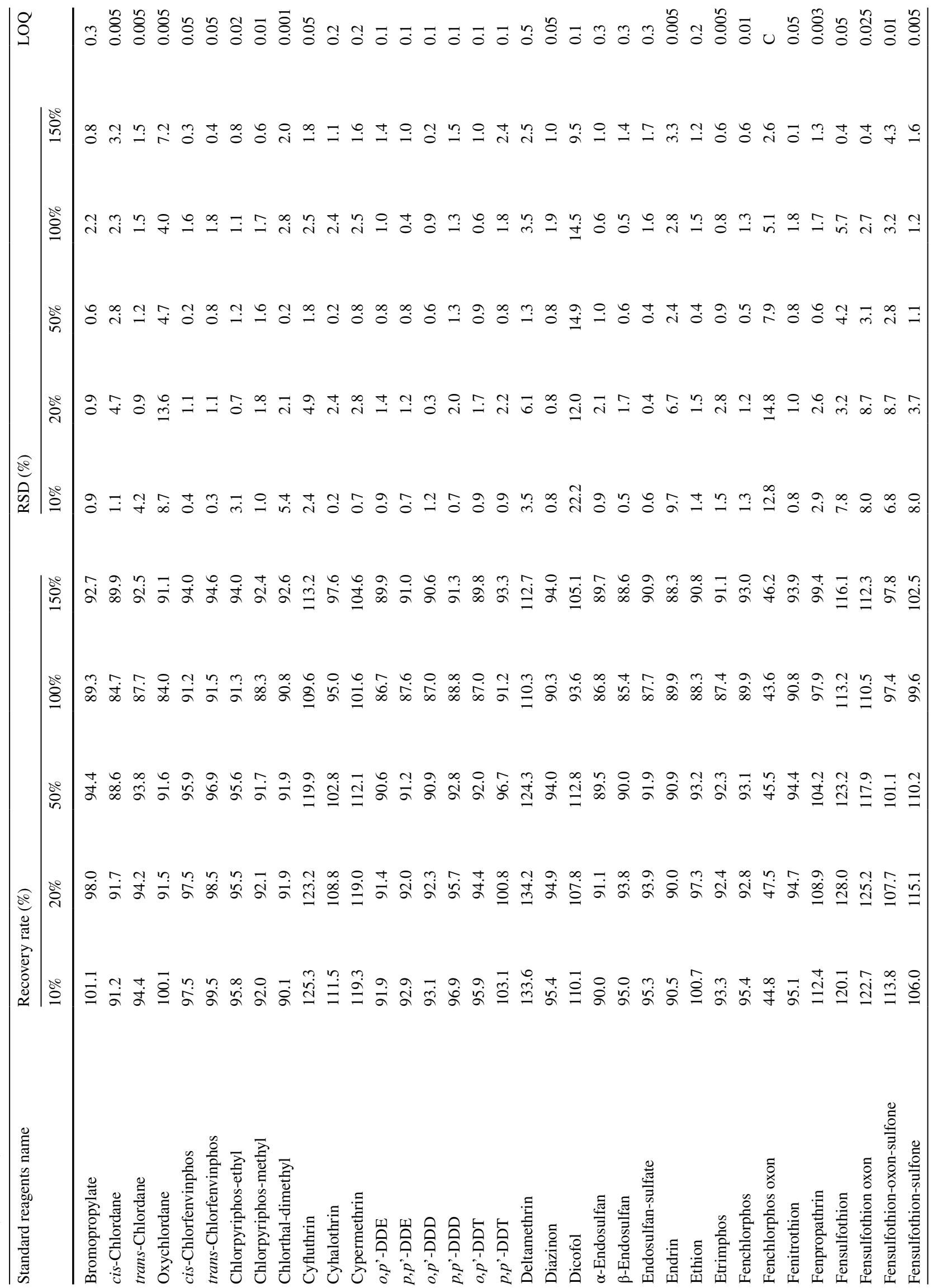




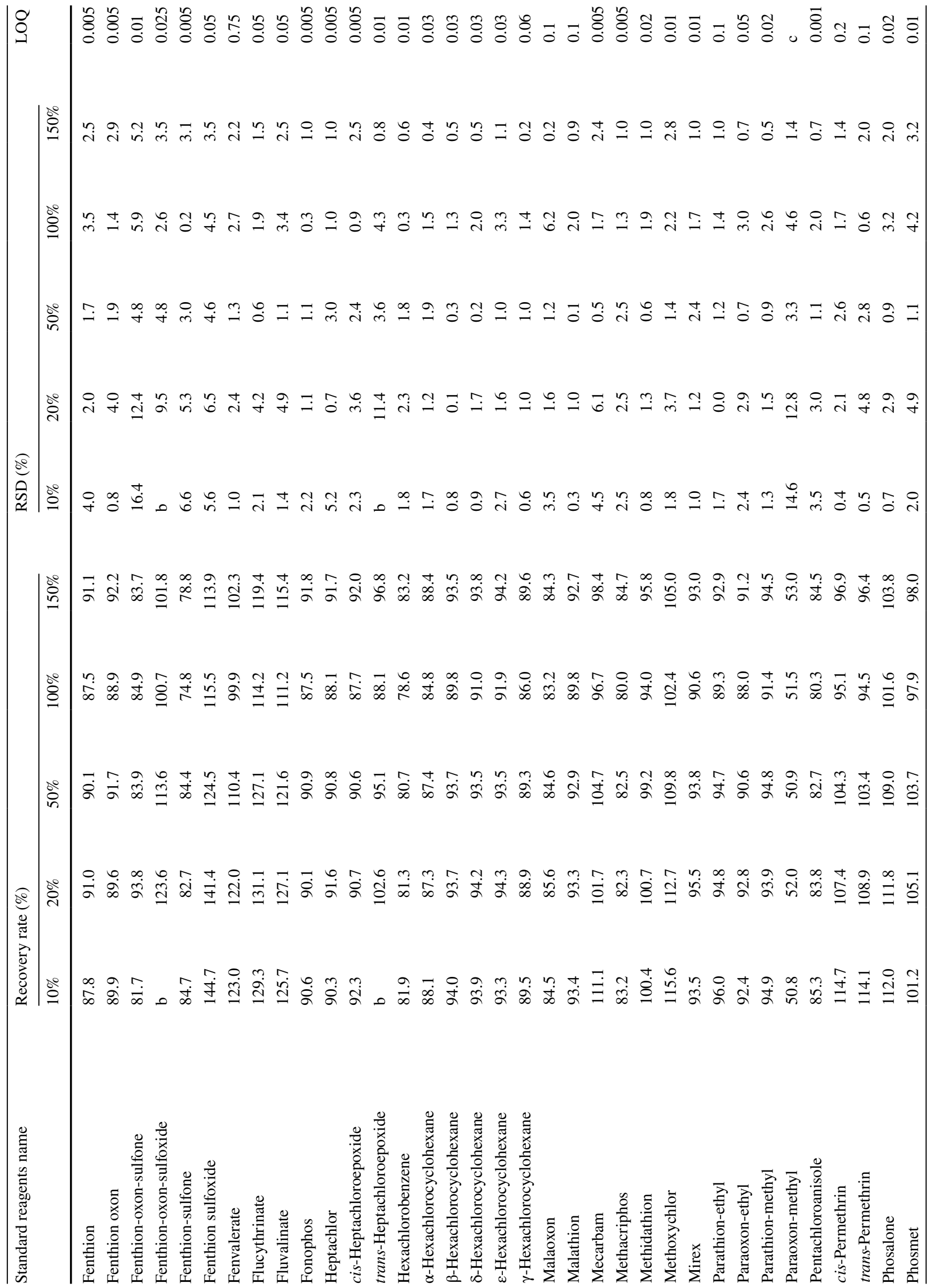




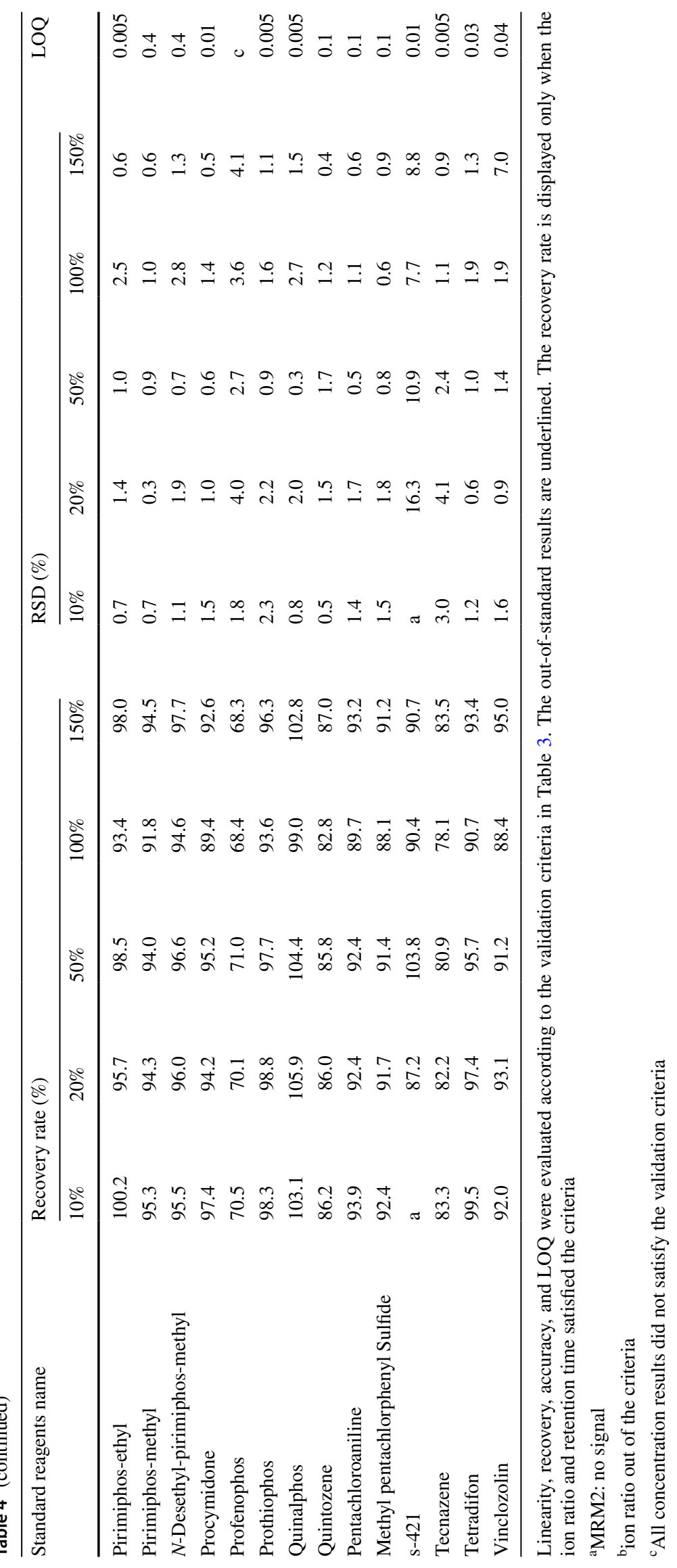




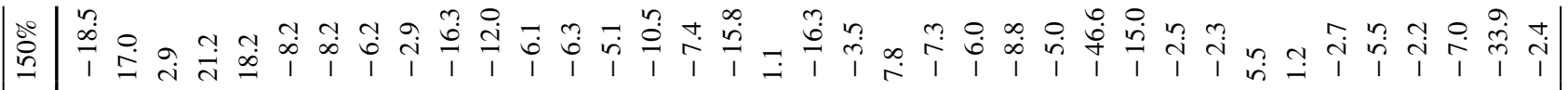

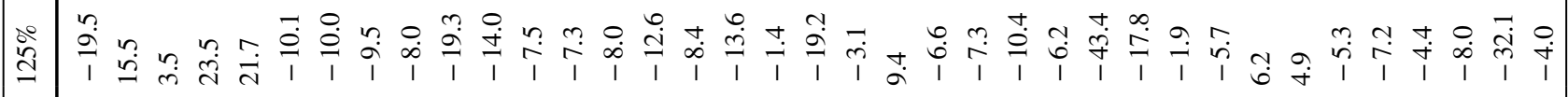
过

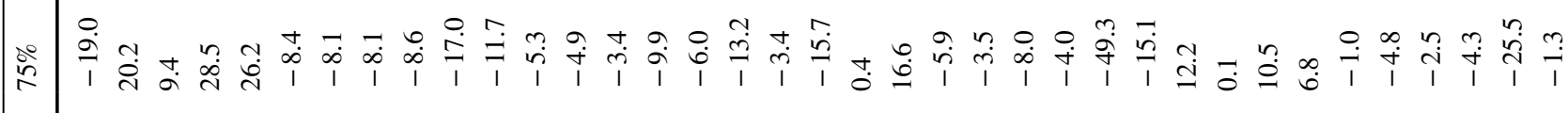

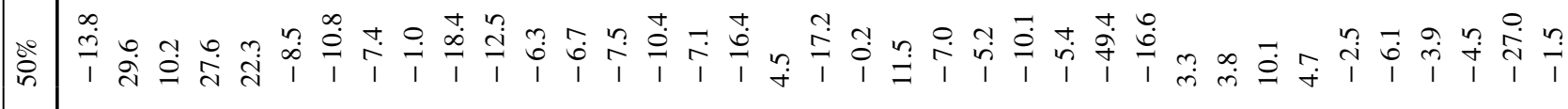

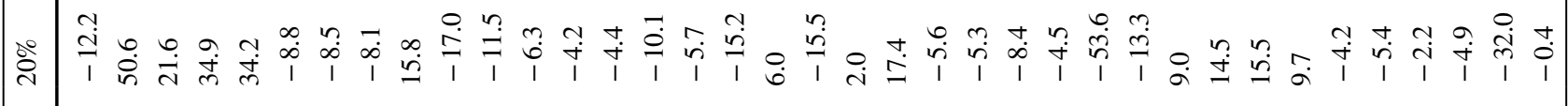

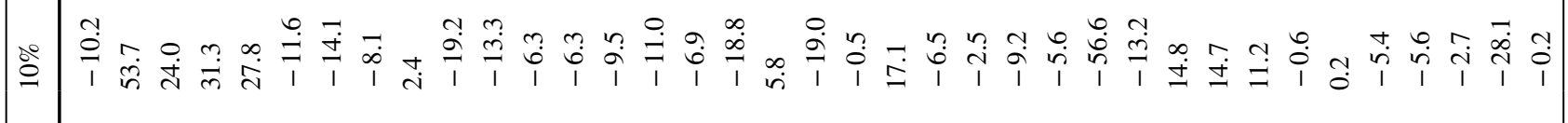
芵

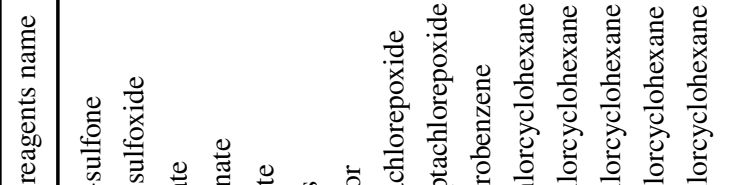

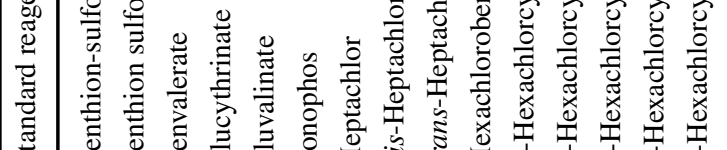
苛过

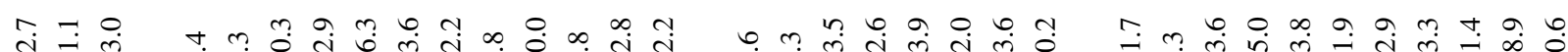

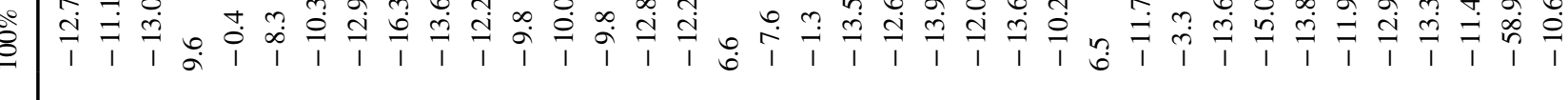

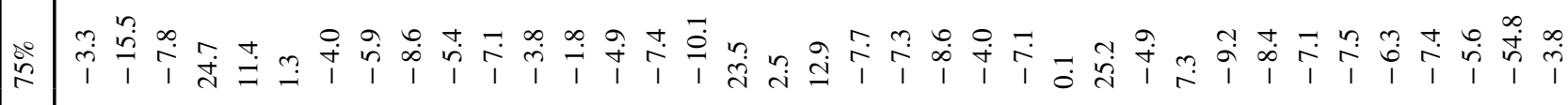

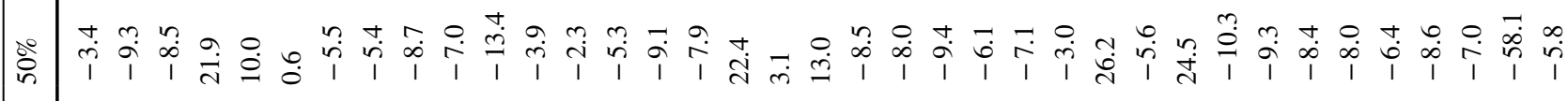
突 m 응 - 
matrices, which originated from DKT, affected the GC-MS/ MS analysis.

For cyhalothrin, deltamethrin, delta-BHC, and dicofol, the recovery rates were less than $70 \%$, or more than $120 \%$, in the evaluation of the purification column without the matrix effect inhibitor, although it was within the range with the matrix effect inhibitor. It is known that cyhalothrin and deltamethrin are transformed into their respective isomers by heat during GC analysis [21]. Dicofol is known to be decomposed by heat during GC analysis, and its decomposition product, 4,4'-dichlorobenzophenone, was the subject of analysis [22]. Furthermore, it was inferred that l-gulonic acid $\gamma$-lactone maintained the constant ratio of the isomers or decomposition products in the acetone and DKT sample solutions. For the delta-BHC, it was inferred that the recovery rate was recuperated because GC analysis was stabilized by the influence of 1-gulonic acid $\gamma$-lactone.

For bromopropylate, fensulfothion, fensulfothion oxon, fensulfothion-oxon-sulfone, fenthion-oxon-sulfoxide, and fenthion sulfoxide, cyhalothrin, deltamethrin, delta-BHC, and dicofol, it may be challenging to guarantee the quality of the performance of the analysis method when the test environment and the operators change. When performing routine tests, it may be necessary to be extra cautious and confirm its performance on a periodic basis [17]. It is very likely that the recovery rates of these pesticides would become abnormal values when the method is applied to other herbal medicines other than DKT. Therefore, particular attention should be given to the development of analysis methods for other herbal medicines other for DKT. Further, for the 16 pesticides (acephate, bromide, dichlofluanid, dichlorvos, dimethoate, omethoate, dithiocarbamates, methamidophos, monocrotophos, piperonyl butoxide, cinerin I, cinerin II, jasmolin I, jasmolin II, pyrethrin I, and pyrethrin II) that were not analyzed in this study, it is necessary to consider alternative analysis methods other than GC-MS/MS in view of the chemical properties of these compounds.

\section{Conclusion}

Here, we developed an analytical method for testing 91 USP-listed compounds, employing DKT as the subject. The method could extract pesticides from DKT with acetone, elute them from a SepPak C18 (5 g) column with acetonitrile, elute them from a DSC- $\mathrm{NH}_{2}(2 \mathrm{~g})$ column with ethyl acetate, and perform simultaneous analysis by GC-MS/MS. This analytical method was validated according to USP and proved that 88 compounds were quantifiable. The analytical method developed in this study could enable the analysis of the metabolites of organophosphorus pesticides, which had not been analyzed and increase the number of compounds that could be analyzed. 


\section{Compliance with ethical standards}

Conflict of interests Yuzo Kodama and Masaru Yoshida received a research grant from Tsumura and Co. Hirokazu Saegusa, Hiroshi Nomura, Masaki Takao, and Takashi Hamaguchi are employees of Tsumura and Co.

Open Access This article is licensed under a Creative Commons Attribution 4.0 International License, which permits use, sharing, adaptation, distribution and reproduction in any medium or format, as long as you give appropriate credit to the original author(s) and the source, provide a link to the Creative Commons licence, and indicate if changes were made. The images or other third party material in this article are included in the article's Creative Commons licence, unless indicated otherwise in a credit line to the material. If material is not included in the article's Creative Commons licence and your intended use is not permitted by statutory regulation or exceeds the permitted use, you will need to obtain permission directly from the copyright holder. To view a copy of this licence, visit http://creativecommons.org/licenses/by/4.0/.

\section{References}

1. (2007) WHO guidelines for assessing quality of herbal medicines with reference to contaminants and residues; 2007

2. Motoo Y, Seki T, Tsutani K (2011) Traditional Japanese medicine, kampo: its history and current status. Chin J Integr Med 17(2):85-87. https://doi.org/10.1007/s11655-011-0653-y

3. Kubota K, Mase A, Matsushima H, Fujitsuka N, Yamamoto M, Morine Y, Taketomi A, Kono T, Shimada M (2019) Daikenchuto, a traditional Japanese herbal medicine, promotes colonic transit by inducing a propulsive movement pattern. Neurogastroenterol Motil 31(11):e13689. https://doi.org/10.1111/nmo.13689

4. Manabe N, Camilleri M, Rao A, Wong BS, Burton D, Busciglio I, Zinsmeister AR, Haruma K (2010) Effect of Daikenchuto (TU100) on gastrointestinal and colonic transit in humans. Am J Physiol Gastrointest Liver Physiol 298(6):G970-G975. https:// doi.org/10.1152/ajpgi.00043.2010

5. Kono T, Shimada M, Nishi M, Morine Y, Yoshikawa K, Katsuno H, Maeda K, Koeda K, Morita S, Watanabe M, Kusano M, Sakamoto J, Saji S, Sokuoka H, Sato Y, Maehara Y, Kanematsu T, Kitajima M (2019) Daikenchuto accelerates the recovery from prolonged postoperative ileus after open abdominal surgery: a subgroup analysis of three randomized controlled trials. Surg Today 49(8):704-711. https://doi.org/10.1007/s00595-019-01787 $-9$

6. (1992) Codex Alimentarius Commission. Codex maximum limits for pesticide residues, Part 2; April 1992

7. Japanese pharmacopoeia. Tokyo: Ministry of Health, Labour and Welfare; 2016. 17th ed [internet]

8. United States Pharmacopeia. General chapter $<561>$ articles of botanical origin USP38-NF33. p. 38

9. European pharmacopoeia: chapter 2.2.66. Detection and measurement of radioactivity, 01/2017. In: 9 th ed. Vol. 1
10. Wong JW, Zhang K, Tech K, Hayward DG, Krynitsky AJ, Cassias I, Schenck FJ, Banerjee K, Dasgupta S, Brown D (2010) Multiresidue pesticide analysis of ginseng powders using acetonitrileor acetone-based extraction, solid-phase extraction cleanup, and gas chromatography-mass spectrometry/selective ion monitoring (GC-MS/SIM) or -Tandem mass spectrometry (GC-MS/MS). J Agric Food Chem 58(10):5884-5896. https://doi.org/10.1021/ jf903851h

11. Li S, Yu P, Zhou C, Tong L, Li D, Yu Z, Zhao Y (2020) Analysis of pesticide residues in commercially available Chenpi using a modified QuEChERS method and GC-MS/MS determination. J Pharm Anal 10(1):60-69. https://doi.org/10.1016/j. jpha.2019.01.005

12. Thompson S, Budzinski H, LeMenach K, Letellier M, Garrigues P (2002) Multi-residue analysis of polycyclic aromatic hydrocarbons, polychlorobiphenyls, and organochlorine pesticides in marine sediments. Anal Bioanal Chem 372(1):196-204. https:// doi.org/10.1007/s00216-001-1170-1

13. Pesticide analytical manual Chapter 3. 3rd ed. Vol. I (PAM)

14. Sohn SH, Kim SK, Kang HG, Wee JJ (2004) Two-phase partition chromatography using soybean oil eliminates pesticide residues in aqueous ginseng extract. J Chromatogr A 1042(1-2):163-168. https://doi.org/10.1016/j.chroma.2004.05.029

15. Štajnbaher D, Zupančič-Kralj L (2003) Multiresidue method for determination of 90 pesticides in fresh fruits and vegetables using solid-phase extraction and gas chromatography-mass spectrometry. J Chromatogr A 1015(1-2):185-198. https://doi.org/10.1016/ S0021-9673(03)01211-1

16. (2008) Handbook of food analysis instruments/editor, Semih Otles, Chapter 7. In: Gas chromatography in food analysis; 2008

17. SANCO (2013SANTE 2017). Guidance document on analytical quality control and validation procedures method validation procedures for pesticide residues and analysis in food and feed. Document No SANCO/12571/201311813/2017

18. Kirchner M, Matisová E, Otrekal R, Hercegová A, Zeeuw Jd (2005) Search on ruggedness of fast gas chromatography-mass spectrometry in pesticide residues analysis. J Chromatogr A 1084(1-2):63-70. https://doi.org/10.1016/j.chroma.2004.10.043

19. Sánchez-Brunete C, Albero B, Martín G, Tadeo JL (2005) Determination of pesticide residues by GC-MS using analyte protectants to counteract the matrix effect. Anal Sci 21(11):1291-1296. https://doi.org/10.2116/analsci.21.1291

20. 〈1225〉 United States Pharmacopeia. General chapter. Validation of compendial procedures USP38-NF33. p. 38

21. Liu W, Qin S, Gan J (2005) Chiral stability of synthetic pyrethroid insecticides. J Agric Food Chem 53(10):3814-3820. https://doi. org/10.1021/jf048425i

22. Mastovská K, Lehotay SJ (2004) Evaluation of common organic solvents for gas chromatographic analysis and stability of multiclass pesticide residues. J Chromatogr A 1040(2):259-272. https ://doi.org/10.1016/j.chroma.2004.04.017

Publisher's Note Springer Nature remains neutral with regard to jurisdictional claims in published maps and institutional affiliations. 